\title{
IDENTIFIKASI GRADE PADA BIBIT SAPI ACEH BETINA DI PUSAT PEMBIBITAN INDRAPURI
}

\author{
W. P. B. PUTRA ${ }^{*}{ }^{*}$, SUMADI $^{2}$, T. HARTATIK² DAN H. SAUMAR ${ }^{3}$ \\ ${ }^{1}$ Laboratorium Reproduksi, Pemuliaan dan Kultur Sel Hewan, Pusat Penelitian Bioteknologi - LIPI \\ Jl. Bogor-Jakarta Km. 46, Cibinong, Bogor, Jawa Barat, 16911 \\ ${ }^{2}$ Program Studi Produksi Ternak, Fakultas Peternakan, Universitas Gadjah Mada Yogyakarta \\ Jl. Fauna No. 3 Bulaksumur, Yogyakarta, 55281 \\ ${ }^{3}$ Balai Pembibitan Ternak Unggul - Hijauan Pakan Ternak (BPTU-HPT) Sapi Aceh Indrapuri \\ Jl. Medan-Banda Aceh Km. 25 Indrapuri, Aceh, 23363 \\ Korespondensi E-mail: widya.putra.lipi@gmail.com / banchet_putra18@yahoo.co.id
}

\begin{abstract}
Grade identification on cattle seedstock were usefull for grouped of livestock based on certain performance for the livestock selection. This study was carried out to identify the grade in Aceh heifer seedstock that kept at BPTU-HPT Sapi Aceh Indrapuri based on standard for Aceh heifer seedstock (SNI 7651.3.2013). Records data from year 2010 - 2013 consisted of withers height $(W H)$, body length $(B L)$, heart girth $(H G)$ and body weight $(B W)$ from 54 animals were used for data analysis through SPSS 16.0 program. The average of female Aceh cattle at $497.91+29.43$ days of age were $87.44+4.87 \mathrm{~cm}$ $(W H) ; 80.80 \pm 6.19 \mathrm{~cm}(B L) ; 101.29 \pm 10.40 \mathrm{~cm}(\mathrm{HG})$ dan $86.20 \pm 18.77 \mathrm{~kg}(\mathrm{BW})$. Total of 26 cattle $(48.14 \%)$ were appropriated to SNI and consisted of grade I (6 animals/23,07\%), grade II (8 animals/30,77\%) and grade III (12 animals $/ 46,15 \%)$. Research showed that the average of BW in all registered seedstock (according to SNI) was higher $(97.67+16.67 \mathrm{~kg})$ than unregistered seedstock $(75.55+13.80 \mathrm{~kg})$.
\end{abstract}

Keywords : Aceh cattle, Performance, Seedstock, SNI, Grade

\section{PENDAHULUAN}

Sapi Aceh merupakan salah satu sapi yang beradaptasi dengan baik di Provinsi Aceh dan telah ditetapkan menjadi salah satu rumpun sapi lokal di Indonesia melalui Keputusan Menteri Pertanian RI nomor: 2907/KPTS/OT.140/6/2011. Sapi Aceh memiliki potensi genetik yang baik antara lain nilai persentase karkas mencapai 55,75+0,67\% (Fitri, 1991). Dijelaskan lebih lanjut bahwa rata-rata kandungan bahan kering dan protein pada daging sapi Aceh lebih tinggi dibandingkan dengan sapi Friesian Holstein dan Brahman Cross. Beberapa sifat reproduksi Aceh betina menurut Bakhtiar (2010) antara lain umur pertama kali dikawinkan $(23,80 \pm 2.25$ bulan), lama siklus birahi $(19,80 \pm 1,16$ hari), lama bunting $(274,20 \pm 3,45$ hari), kawin kembali setelah beranak $(127,00 \pm 33,13$ hari), Service per Conception $(1,13)$ dan conception rate (91\%).

Upaya untuk meningkatkan mutu genetik sapi Aceh sangat diperlukan agar kebutuhan daging sapi masyarakat dapat dipenuhi dari dalam negeri. Tercatat pada tahun 2015 produksi daging sapi nasional sebesar 506.661 ton (Kementan, 2016) sedangkan proyeksi konsumsi daging nasional mencapai 639.857,57 ton (Anonimous, 2014). Berdasarkan data tersebut maka terdapat defisit daging sapi sebesar 133.196, 57 ton dan harus dipenuhi dari impor. Peningkatan mutu genetik ternak dapat dilakukan dengan cara melakukan seleksi ternak berdasarkan performans. Performans pada ternak yang digunakan untuk seleksi ternak antara lain tinggi gumba, panjang badan, lingkar dada dan berat badan (Supiyono, 1998). 
Pada tahun 2013 telah diterbitkan Standar Nasional Indonesia (SNI 7651.3.2013) untuk bibit sapi Aceh. Standar SNI bibit sapi tersebut sangat penting untuk mengklasifikasi performans sapi kedalam tiga tipe kelas (grade). Sapi Aceh yang memenuhi persyaratan SNI selanjutnya harus digunakan untuk program breeding agar menghasilkan pedet-pedet yang unggul. Balai Pembibitan Ternak Unggul - Hijauan Pakan Ternak (BPTU-HPT) Sapi Aceh Indrapuri merupakan salah satu pusat pembibitan sapi Aceh yang bertanggung jawab untuk menerapkan Good Breeding Practice (GBP). Identifikasi grade pada sapi Aceh betina di lokasi tersebut sangat penting dilakukan agar diperoleh bibit calon induk yang baik. Penelitian tentang identifikasi grade pernah dilakukan oleh Soekardono et al. (2009) dan Ishak et al. (2014) terhadap sapi Bali betina. Berdasarkan informasi yang telah dikemukakan diatas, maka perlu dilakukan penelitian tentang identifikasi grade pada sapi Aceh betina berdasarkan semua kriteria ukuran tubuh agar diperoleh bibit sapi Aceh betina (calon induk) yang sesuai SNI.

\section{METODE PENELITIAN}

\section{Lokasi Penelitian}

Penelitian ini dilakukan di BPTU-HPT Sapi Aceh Indrapuri yang terletak di Kecamatan Indrapuri, Provinsi Aceh. Secara astronomi lokasi ini terletak di 00 5033'22.5821 LU dan 95025'21.5969 BB dan berada di 300 - 800 dpl. Wilayah ini memiliki iklim yang panas dengan ratarata suhu udara 20,60 ${ }^{\circ} \mathrm{C}$ dengan rata-rata kelembaban udara $84,83 \%$ dan rata-rata curah hujan $1147 \mathrm{~mm} /$ tahun.

\section{Materi Penelitian}

Penelitian ini dilakukan dengan menggunakan data primer berupa catatan (recording) tahun 2010 sampai 2013 dari 54 ekor sapi Aceh betina. Data recording ternak yang digunakan pada penelitian ini meliputi data kelahiran, data berat badan (BB) dan ukuran tubuh. Data ukuran tubuh terdiri dari tinggi gumba (TG), panjang badan $(\mathrm{PB})$ dan lingkar dada (LD). Data BB diperoleh dengan cara menimbang ternak menggunakan timbangan ternak dengan posisi tegak lurus dengan bidang datar (parallelogram). Data TG diperoleh dengan menggunakan tongkat ukur dari bagian pundak sampai ke permukaan tanah mengikuti garis tegak lurus. Data PB diperoleh dengan cara mengukur jarak antara sendi bahu (later tuberosity of humerus) sampai ke tepi belakang tulang pelvis dengan menggunakan tongkat ukur. Data LD diperoleh dengan cara melingkarkan pita ukur pada bagian dada atau tubuh di belakang bahu. Skema pengukuran tubuh pada sapi Aceh tersaji pada Gambar 1.

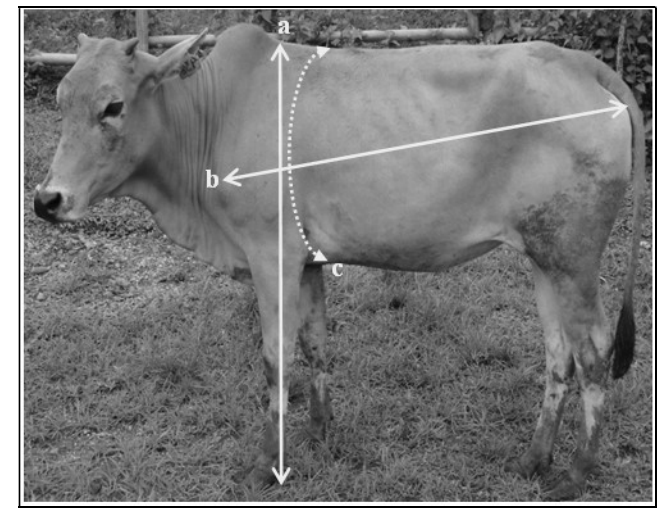

Gambar 1. Skema pengukuran tubuh tinggi gumba (a), panjang badan (b) dan lingkar dada (c) pada sapi Aceh betina di BPTU-HPT Sapi Aceh Indrapuri.

\section{Analisis Data}

Data berat badan dan ukuran tubuh yang diperoleh selanjutnya dianalisis secara menggunakan program komputer SPSS 16.0 untuk memperoleh nilai ratarata, standar deviasi (SD), koefisien variasi 
$(\mathrm{KV})$, nilai minimum dan nilai maksimum. Data performans pada semua sapi Aceh yang terpilih berdasarkan SNI selanjutnya dibandingkan dengan sapi Aceh non SNI menggunakan metode analisis independent sample T-test untuk mengetahui pengaruh grade terhadap performans.

\section{Grading Sapi Aceh}

Data ukuran tubuh individu yang diperoleh selanjutnya dibandingkan dengan SNI bibit sapi Aceh betina seperti yang tercantum pada Tabel 1. Individu yang salah satu ukuran tubuhnya tidak sesuai SNI maka individu tersebut tidak memiliki grade. Demikian pula apabila terdapat individu yang memiliki kasus dimana terdapat 2 ukuran tubuh yang memenuhi syarat grade I / II dan 1 ukuran tubuh yang memenuhi syarat grade III, maka individu tersebut dikategorikan sebagai grade III. Dasar penilaian tersebut adalah bahwa nilai SNI ukuran tubuh minimum pada bibit sapi Aceh betina harus tercapai. Contoh cara identifikasi grade pada sapi Aceh betina secara lengkap tersaji pada Tabel 2.

Tabel 1. Persyaratan minimum ukuran tubuh sapi Aceh betina umur 450 - 550 hari (SNI 7651.3.2013).

\begin{tabular}{cccc}
\hline Grade & \multicolumn{3}{c}{ Pengukuran $(\mathrm{cm})$} \\
\cline { 2 - 4 } & Tinggi gumba & Panjang badan & Lingkar dada \\
\hline I & 90 & 87 & 99 \\
II & 88 & 84 & 97 \\
III & 86 & 82 & 94 \\
\hline
\end{tabular}

Tabel 2. Contoh cara identifikasi grade pada sapi Aceh betina

\begin{tabular}{|c|c|c|c|c|c|c|}
\hline \multirow[t]{2}{*}{ Kasus } & \multirow[t]{2}{*}{ Ukuran tubuh } & \multicolumn{4}{|c|}{ Identifikasi grade } & \multirow[t]{2}{*}{ Penilaian } \\
\hline & & Grade I & Grade II & Grade III & Non-grade & \\
\hline \multirow{3}{*}{1} & Tinggi gumba & $\sqrt{ }$ & - & - & - & \multirow{3}{*}{ Non-grade } \\
\hline & Panjang badan & $\sqrt{ }$ & - & - & - & \\
\hline & Lingkar dada & - & - & - & $\sqrt{ }$ & \\
\hline \multirow{3}{*}{2} & Tinggi gumba & $\sqrt{ }$ & - & - & - & \multirow{3}{*}{ Grade II } \\
\hline & Panjang badan & $\sqrt{ }$ & - & - & - & \\
\hline & Lingkar dada & - & $\sqrt{ }$ & - & - & \\
\hline \multirow{3}{*}{3} & Tinggi gumba & $\sqrt{ }$ & - & - & - & \multirow{3}{*}{ Grade III } \\
\hline & Panjang badan & - & $\sqrt{ }$ & - & - & \\
\hline & Lingkar dada & - & - & $\sqrt{ }$ & - & \\
\hline
\end{tabular}

\section{HASIL DAN PEMBAHASAN}

\section{Berat Badan}

Deskriptif statistik BB sapi Aceh betina pada penelitian ini tersaji pada Tabel 3 . Rata-rata BB sapi Aceh betina pada penelitian ini lebih rendah dari hasil penelitian Abdullah et al. (2006) pada sapi
Aceh umur 1 tahun yaitu sebesar $116,70 \pm 25,83 \mathrm{~kg}$ (BB). Rata-rata BB pada Sapi Bali betina umur 1 - 2 tahun di Pulau Seram sebesar 214,29 $\pm 65,00 \quad \mathrm{~kg}$ (Latulumamina, 2013) dan di Kabupaten Timor Tengah Utara sebesar 118,88+8,75 $\mathrm{kg}$ (Tonbesi et al., 2009) dan lebih tinggi dibandingkan dengan sapi Aceh. Rata-rata BB sapi Pesisir dan PO betina umur 2 
tahunan masing-masing sebesar $104,60 \pm 29,00 \mathrm{~kg}$ dan 284,80+54,50 kg (Adrial, 2010; Hartati et al., 2009). Berat badan sapi Aceh $(116,70 \mathrm{~kg})$ terlihat lebih tinggi dibandingkan dengan BB sapi Pesisir (104,60 kg). Rata-rata BB sapi Aceh betina terlihat lebih tinggi dibandingkan dengan sapi Red Chittagong (Bos indicus) betina di Bangladesh yaitu sebesar $70.74+2.02 \mathrm{~kg}$ (Nahar et al., 2016).

\section{Ukuran Tubuh}

Rata-rata ukuran tubuh pada sapi Aceh betina menunjukkan nilai yang lebih rendah dibandingkan dengan ukuran tubuh pada beberapa sapi lokal lain di Indonesia seperti pada Tabel 3. Walaupun demikian, ukuran tubuh TG dan PB pada sapi Aceh tidak berbeda jauh dengan sapi Pesisir. Rata-rata ukuran tubuh spai Aceh betina dalam penelitian juga lebih rendah dari penelitian sebelumnya yang dilakukan oleh Abdullah et al. (2007).

Tabel 3. Rata-rata ukuran tubuh sapi Aceh dan beberapa sapi lokal betina lainnya umur 2 tahunan.

\begin{tabular}{|c|c|c|c|c|}
\hline \multirow[t]{2}{*}{ Bangsa } & \multicolumn{3}{|c|}{ Ukuran tubuh $(\mathrm{cm})$} & \multirow[t]{2}{*}{ Sumber referensi } \\
\hline & TG & PB & LD & \\
\hline Aceh & $96,10 \pm 4,23$ & $98,59 \pm 6,10$ & $124,69 \pm 6,47$ & Abdullah et al. (2007) \\
\hline Bali & $96,50 \pm 6,86$ & $96,50+4,73$ & $122,75+4,57$ & Tonbesi et al. (2009) \\
\hline Madura & $113,55+5,59$ & $111,60 \pm 7,02$ & $136,89 \pm 4,93$ & Setiadi dan Diwyanto (1997) \\
\hline $\mathrm{PO}$ & $119,90 \pm 8,80$ & $124,30 \pm 7,10$ & $151,80 \pm 10,20$ & Hartati et al. (2009) \\
\hline Katingan & $102,90 \pm 4,50$ & $112,70 \pm 7,70$ & $141,40 \pm 5,70$ & Utomo et al. (2010) \\
\hline Pesisir & $90,40 \pm 7,00$ & $95,90+9,00$ & $109,90 \pm 11,80$ & Adrial (2010) \\
\hline \multicolumn{5}{|l|}{ Aceh } \\
\hline SNI $(\mathrm{N}=26)$ & $90,46 \pm 2,79 a$ & $85,38+3,94$ & $107,42 \pm 6,57 a$ & Hasil penelitian \\
\hline Non SNI $(\mathrm{N}=28)$ & $84,64 \pm 4,73^{b}$ & $76,54 \pm 4,67$ & $95,59 \pm 10,12^{b}$ & Hasil penelitian \\
\hline Grade I $(\mathrm{N}=6)$ & $93,25 \pm 1,47 a$ & $90,50 \pm 3,08^{a}$ & $111,67 \pm 4,68$ & Hasil penelitian \\
\hline Grade II $(\mathrm{N}=8)$ & $90,38+3,29 b$ & $84,88+3,18^{b}$ & $106,38+7,44$ & Hasil penelitian \\
\hline Grade III $(\mathrm{N}=12)$ & $89,13 \pm 1,91^{b}$ & $83,17 \pm 2,17 b$ & $106,00 \pm 6,32$ & Hasil penelitian \\
\hline Total $(\mathrm{N}=54)$ & $87,44+4,87$ & $80,80 \pm 6,19$ & $101,29 \pm 10,40$ & Hasil penelitian \\
\hline
\end{tabular}

Keterangan: $\mathrm{a}, \mathrm{b}$ superskrip yang menunjukkan perbedaan signifikan $(\mathrm{P}<0,05)$ pada faktor yang sama; $\mathrm{N}=$ jumlah individuTG= tinggi gumba; $\mathrm{PB}=$ panjang badan; $\mathrm{LD}=$ lingkar dada; $\mathrm{SNI}=$ standar nasional Indonesia.

\section{Grading}

Hasil identifikasi grade pada calon bibit sapi Aceh betina terlihat bahwa dari 54 ekor calon bibit yang dievaluasi, hampir setengahnya saja (26 ekor) yang sesuai SNI dan terbagi atas grade I (6 ekor $/ 23,07 \%$ ), grade II (8 ekor/30,77\%) dan grade III (12 ekor/46,15\%). Jumlah sapi Aceh betina yang memenuhi kriteria bibit grade I masih sedikit dan paling banyak adalah grade III. Hasil penelitian menunjukkan bahwa secara keseluruhan syarat minimum pada LD pada masing-masing grade sudah dicapai pada penelitian ini, akan tetapi rata-rata PB masih belum jauh diatas nilai SNI seperti yang terlihat pada Tabel 3 . Ishak et al. (2014) melaporkan bahwa sebagian besar hasil grading sapi Bali betina di Kecamatan Taneteriaja, Sulawesi Selatan adalah grade II $(81,09 \%)$.

Hasil identifikasi grade pada sapi Aceh betina di BPTU-HPT sapi Aceh telah diperoleh lima ekor calon induk sapi Aceh terbaik pada masing-masing grade seperti yang tersaji pada Tabel 4. Rata-rata ukuran tubuh sapi Aceh betina umur 
sekitar 500 hari sudah dapat memenuhi kriteria SNI. Sapi Aceh betina yang berumur lebih dari 550 hari dan memenuhi kriteria SNI, maka sapi tersebut tidak termasuk kriteria bibit karena tidak memenuhi syarat umur. Sapi yang belum memenuhi syarat SNI dapat dievaluasi kembali pada saat berumur 550 hari.

Tabel 4. Performans lima bibit sapi Aceh betina terbaik per kelas berdasarkan berat badan di BPTU-HPT Sapi Aceh Indrapuri.

\begin{tabular}{|c|c|c|c|c|c|c|c|}
\hline \multirow{2}{*}{ Grade } & \multirow{2}{*}{ Peringkat } & \multirow{2}{*}{ No. Sapi } & \multicolumn{5}{|c|}{ Performans } \\
\hline & & & $\begin{array}{l}\text { Umur } \\
\text { (hari) }\end{array}$ & $\begin{array}{c}\text { TG } \\
(\mathrm{cm})\end{array}$ & $\begin{array}{c}\mathrm{PB} \\
(\mathrm{cm})\end{array}$ & $\begin{array}{l}\text { LD } \\
(\mathrm{cm})\end{array}$ & $\begin{array}{c}\text { BB } \\
(\mathrm{kg})\end{array}$ \\
\hline \multirow{5}{*}{ I } & 1 & A100526 & 519 & 92 & 91 & 115 & 130 \\
\hline & 2 & A100302 & 513 & 96 & 95 & 118 & 118 \\
\hline & 3 & A1015 & 531 & 94 & 93 & 112 & 112 \\
\hline & 4 & A100514 & 533 & 93 & 89 & 105 & 109 \\
\hline & 5 & A110609 & 488 & 93 & 88 & 112 & 106 \\
\hline \multirow{5}{*}{ II } & 1 & A100807 & 536 & 98 & 84 & 118 & 114 \\
\hline & 2 & A100607 & 487 & 88 & 87 & 109 & 105 \\
\hline & 3 & A100123 & 547 & 88 & 89 & 115 & 102 \\
\hline & 4 & A100404 & 477 & 91 & 86 & 109 & 100 \\
\hline & 5 & A100310 & 508 & 89 & 85 & 101 & 86 \\
\hline \multirow{5}{*}{ III } & 1 & A100408 & 474 & 90 & 82 & 116 & 127 \\
\hline & 2 & A216 & 474 & 86 & 86 & 117 & 124 \\
\hline & 3 & A100518 & 530 & 91 & 82 & 112 & 101 \\
\hline & 4 & A100425 & 465 & 87 & 89 & 102 & 94 \\
\hline & 5 & A100126 & 472 & 91 & 82 & 108 & 93 \\
\hline
\end{tabular}

Keterangan: $\mathrm{TG}=$ tinggi gumba; $\mathrm{PB}=$ panjang badan; $\mathrm{LD}=$ lingkar dada; $\mathrm{BB}=$ berat badan .

\section{KESIMPULAN}

Sebagian besar calon bibit sapi Aceh di BPTU-HPT Sapi Aceh Indrapuri termasuk kategori grade III $(46,15 \%)$ sehingga seleksi ternak berdasarkan ukuran tubuh sangat penting dilakukan agar diperoleh individu-individu baru yang memenuhi syarat SNI.

\section{UCAPAN TERIMA KASIH}

Penulis mengucapkan terima kasih kepada seluruh staf Pengawas Bibit Ternak (WASBITNAK) di BPTU-HPT Sapi Aceh Indrapuri atas bantuan dan partisipasinya sehingga penelitian ini dapat diselesaikan dengan baik.

\section{DAFTAR PUSTAKA}

Abdullah, M.A.N., R.R. Noor, H. Martojo, D.D. Solihin dan E. Hendiwirawan. 2006. Keragaman fenotipik sapi Aceh di Nanggroe Aceh Darussalam. J. Indon. Trop. Anim. Agric. 32(1): 11-21.

Adrial. 2010. Potensi sapi Pesisir dan upaya pengembangannya di Sumatera Barat. J. Litbang Pertanian. 29(2): 66-72. 
Bakhtiar. 2010. Performans reproduksi dan produksi sapi Aceh. Tesis. Program Pascasarjana.Universitas Andalas. Padang.

Fitri, C.A. 1991. Perbandingan Karkas Dari Spesies Sapi. http://www.poliven.ac.id. 14 November 2016.

Hartati, Sumadi, dan T. Hartatik. 2009. Identifikasi karakteristik genetik sapi Peranakan Ongole di peternakan rakyat. Buletin Peternakan. 33(2): 64-73.

Ishak, A.B.L., A. Nurhayu, A. Ella, M. Sariubang dan T. Rahmawati. 2014. Seleksi performans induk sapi Bali sebagai upaya pembentukan populasi dasar pada program pembibitan dan pemurnian sapi Bali di Kabupaten Barru Provinsi Sulawesi Selatan. Prosiding Seminar Nasional Peternakan. Makassar. Hal 59-65.

Kementerian Pertanian. 2016. Sub-Sektor Peternakan. http://www.pertanian.go.id. 14 November 2016.

Latulumamina, M. 2013. Korelasi antara umur dan berat badan sapi Bali (Bos sondaicus) di Pulau Seram. Agrinimal. 3(1): 35-40.

Nahar, S., A.F.M.F. Islam, M.A. Haque and A.K.F.H. Bhuiyan. 2016. Animal performance of indigenous Red Chittagong cattle in Bangladesh. Acta Scientiarum. 38(2): 177-182.
Tonbesi, T.T., N. Ngadiono dan Sumadi. 2009. Estimasi dan potensi kinerja sapi Bali di Kabupaten Timor Tengah Utara, Provinsi Nusa Tenggara Timur. Buletin Peternakan. 33(1): 30-39.

Utomo, B.N., R.R. Noor, C. Sumantri, I. Supriatna dan E.D. Gunardi. 2010. Keragaman morfometrik sapi Katingan di Kalimantan Tengah. JITV. 15(3): 220-230.

Anonimous. 2014. Road Map Pengembangan Industri Sapi Potong di Indonesia. http://www.fapet.ugm.ac.id.

November 2016.

Setiadi, B. dan K. Diwyanto. 1997. Karakterisasi morfologis sapi Madura. JITV. 2(4): 218-224.

Soekardono, C. Arman dan L.M. Kasip. 2009. Identifikasi grade sapi Bali betina bibit dan koefisien reproduksi sapi betina di Propinsi Nusa Tenggara Barat. Buletin Peternakan. 33(2): 74-80.

Supiyono. 1998. Ilmu Tilik Ternak. Fakultas Peternakan. Universitas Gadjah Mada, Yogyakarta. 